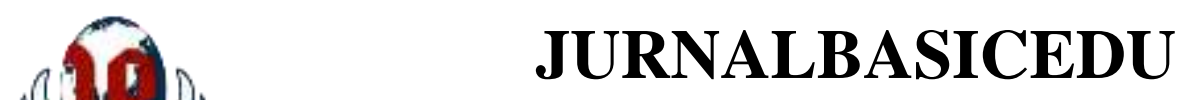

Volume 5 Nomor 6 Tahun 2021 Halaman 5024-5034

Research \&Learningin Elementary Education https://jbasic.org/index.php/basicedu

\title{
Pengembangan Media Articulate Storyline 3 pada Pembelajaran IPA Berbasis STEM untuk Mengembangkan Kreativitas SiswaSD/MI
}

\author{
Siti Nurmala ${ }^{1 凶}$, Retno Triwoelandari ${ }^{2}$, Muhammad Fahri $^{3}$ \\ Universitas Ibn Khaldun Bogor, Indonesia ${ }^{1,2,3}$ \\ E-mail: $\underline{\text { stnurmala0107@ gmail.com }}{ }^{1}, \underline{\text { retnotriwoelandari@uika-bogor.ac.id }}^{2}, \underline{\text { fahri@ fai.uika.ac.id }}^{3}$
}

\begin{abstract}
Abstrak
Penelitian ini dilatar belakangi oleh penggunaan media pembelajaran di sekolah yang masih kurang bervariasi khususnya pada mata pelajaran IPA dan bahan ajar yang digunakan hanya berfokus pada buku paket sekolah sehingga belum mengembangkan kecakapan abad 21 di sekolah dengan baik salah satunya yaitu kreativitas. Maka perlu adanya pengembangan media yang dapat mengembangkan kreativitas siswa. Tujuan penelitian ini yaitu untuk mengetahui kelayakan dan efektifitas media articulate storyline 3 pada pembelajaran IPA berbasis STEM untuk mengembangkan kreativitas siswa. Metode penelitian ini menggunakan metode penelitian dan pengembangan (research and development) dengan menggunakan model penelitian ASSURE. Instrumen penelitian berupa wawancara, angket dan lembar observasi. Hasil dari penelitian ini diperoleh presentase kelayakan penilaian dari ahli materi sebesar 79,8\%, dengan kategori valid, penilaian ahli media sebesar 97,9\% dengan kategori sangat valid, dan penilaian ahli bahasa sebesar 87,5 \% dengan kategori sangat valid. Hasil respon siswa uji perorangan sebesar 95,02\%, uji kelompok kecil sebesar 95,65\%, dan uji kelompok besar sebesar 91,16\%. Berdasarkan hasil tersebut dapat disimpulkan bahwa produk media articulate storyline 3 pada pembelajaran IPA berbasis STEM untuk mengembangkan kreativitas siswa layak dan efektif digunakan dalam proses pembelajaran.
\end{abstract}

Kata Kunci: Articulate storyline, kreativitas, pembelajaran IPA berbasis STEM, pengembangan media

\begin{abstract}
This research is motivated by the use of learning media in schools which are still less varied, especially in science subjects and the teaching materials used only focus on school textbooks so that they have not developed 21 st century skills in schools properly, one of which is creativity, it is necessary to develop media that are can develop students creativity. The purpose of this study is to determine the feasibility and effectiveness of articulate storyline 3 media in STEM-based science learning to develop student creativity. This research method uses reserach and development methods using the ASSURE research model. Research instruments in the from of interviews, questionnaires and observation sheet. The results of this study obtained that the precentage of fesibility assesment frim material experts was $79,8 \%$, in the valid category, the media expert assesment was $97,9 \%$ in the very valid category, and the linguist assesment was $87,5 \%$ in the very valid category. Thre results of the individual test student response were 95,02\%, the small grup test was 95,65\%, and the large group test was 91,16\%. Based on these results, it can be concluded that the media product articulate storyline 3 in STEM-based science learning to develop student creativity is feasible and effective to use in the learning process.
\end{abstract}

Keywords:Articulate storyline, creativity, STEM-based science learning, media development

Copyright (c) 2021 Siti Nurmala, Retno Triwoelandari, Muhammad Fahri

$\triangle$ Corresponding author :

Email : stnurmala0107@gmail.com

DOI $\quad$ : https://doi.org/10.31004/basicedu.v5i6.1546

ISSN 2580-3735 (Media Cetak)

ISSN 2580-1147 (Media Online)

Jurnal Basicedu Vol 5 No 6 Tahun 2021

p-ISSN 2580-3735 e-ISSN 2580-1147 
5025 Pengembangan Media Articulate Storyline 3 pada Pembelajaran IPA Berbasis STEM untuk Mengembangkan Kreativitas SiswaSD/MI - Siti Nurmala, Retno Triwoelandari, Muhammad Fahri

DOI : https://doi.org/10.31004/basicedu.v5i6.1546

\section{PENDAHULUAN}

Pendidikan adalah bagian yang sangat penting dalam kemajuan suatu bangsa, bangsa yang baik salah satunya akan dilihat dari kualitas pendidikannya. Pendidikan adalah upaya yang terorganisasi, berencana dan berlangsung secara terus menerus sepanjang hayat untuk membina anak didik menjadi manusia paripurna dewasa dan berbudaya. Untuk mencapai pembinaan ini asas pendidikan harus berorientasi pada pengembangan seluruh aspek potensi anak didik, diantaranya aspek kognitif, afektif, dan berimplikasi pada aspek psikomotorik (Susanto, 2016). Indonesia memiliki tujuan pendidikan nasional yang tertera pada Undang-Undang Nomor 20 Tahun 2003 adalah mengembangkan potensi peserta didik agar menjadi manusia yang beriman dan bertakwa kepada Tuhan Yang Maha Esa, berakhlak mulia, sehat, berilmu, cakap, kreatif, mandiri dan menjadi warga negara yang demokratis serta bertanggung jawab. Berdasarkan dari tujuan pendidikan nasional tersebut maka sebuah negara harus dapat menciptakan kualitas pendidikan yang baik dengan mengikuti perkembangan dunia pendidikan yang semakin modern ini salah satunya untuk menjawab permasalahan tentang kecakapan di abad 21.

Abad 21 adalah era globaliasai yang ditandai dengan berkembangnya teknologi, komunikasi dan informasi yang semakin berkembang pesat, hal ini pada satu sisi akan berdampak dan berpengaruh sangat positif bagi kemajuan masyarakat suatu bangsa namun juga akan memberikan dampak negatif apabila kurang bijak dalam memanfaatkan teknologi dan informasi yang ada. Era globalisasi ini juga memberikan dampak dalam berbagai bidang, tidak terkecuali pada bidang pendidikan, ada kompetensi abad 21 yang harus dimiliki seseorang yang dipersiapkan untuk dapat berkiprah pada kehidupan nyata. Pendidikan memiliki peran yang sangat penting dalam membantu seseorang memiliki keterampilan dalam menggunakan teknologi, komunikasi dan media informasi yang berkembang saat ini. Pendidikan adalah salah satu jalur yang dapat ditempuh untuk menyiapkan sumber daya manusia yang dapat menguasai kecakapan abad 21 agar dapat bersaing dalam era globalisasi pada abad 21. Seseorang dituntut untuk memiliki kecakapan abad 21, ada empat kecakapan yang harus dimiliki atau dikenal dengan $4 \mathrm{C}$ yaitu, kreativitas (creativity), berpikir kritis (critical thinking), komunikasi (communication), kolaborasi (collaboration)(Maknun et al., 2018).

Pada abad 21 ini Indonesia membutuhkan sumber daya manusia yang unggul, kreatif, dan inovatif, dalam dunia pendidikan dibutuhkan kurikulum sekolah yang dapat mengembangkan aspek tersebut agar dapat membantu siswa dalam mengembangkan keterampilan dan potensi yang dimiliki. Oleh karena itu pembelajaran di sekolah dasar sebaiknya bukan hanya bertujuan untuk pemahaman pengetahuan saja tetapi juga membantu siswa dalam mengembangkan kreativitasnya. Menurut (Munandar, 2016) kreativitas adalah kemampuan yang dimiliki seseorang untuk menciptakan sesuatu yang baru, sebagai kemampuan untuk memberikan gagasan-gagasan baru yang dapat diterapkan dalam pemecahan masalah, atau sebagai kemampuan untuk melihat hubungan-hubungan baru antara unsur-unsur yang sudah ada sebelumnya. Indikator kreativitas siswa menurut Munandar (Susanto, 2016) yaitu memiliki kemampuan berpikir secara lancar (fluency), kemampuan berpikir luwes atau fleksibel (fleksibelity), kemampuan berpikir orisinil (originality), dan kemampuan memperinci (elaboration). Sedangkan menurut (Rachmawati \& Kurniati, 2011) ciri-ciri kreativitas yang ditemukan dalam berbagai studi yaitu, terbuka terhadap pengalaman baru, bebas dalam menyatakan pendapat dan perasaan, tertarik pada kegiatan kreatif, mempunyai pendapat sendiri dan tidak terpengaruh oleh orang lain, mempunyai rasa ingin tahu yang besar, toleran terhadap perbedaan pendapat dan situasi yang tidak pasti, percaya diri dan mandiri, memiliki tanggung jawab dan komitmen kepada tugas, memiliki banyak ide dalam memecahkan masalah, tertarik kepada hal-hal yang bersifat abstrak, kompleks, holistic, dan mengandung teka-teki, memiliki gagasan yang orisinil, mempunyai minat yang luas, kritis terhadap pendapat orang lain, senang mengajukan pertanyaan yang baik.

Dalam peraturan Kemendikbud Nomor 20 Tahun 2016 standar kompetensi lulusan sekolah dasar yaitu dalam dimensi keterampilan memiiki perilaku yang mencerminkan sikap salah satunya kreatif, hal ini 
5026 Pengembangan Media Articulate Storyline 3 pada Pembelajaran IPA Berbasis STEM untuk Mengembangkan Kreativitas SiswaSD/MI - Siti Nurmala, Retno Triwoelandari, Muhammad Fahri

DOI : https://doi.org/10.31004/basicedu.v5i6.1546

menunjukan pentingnya seseorang memiliki kreativitas sebagai bekal dalam menghadapi zaman yang semakin berkembang ini. Namun pada kenyataannya kreativitas siswa masih rendah dan kurang dikembangkan dalam pendidikan formal hal ini ditandai dengan siswa masih kurang terlibat aktif dalam proses pembelajaran sehingga kurang memberikan kesempatan kepada siswa dalam mengembangkan kemampuan dan potensi yang dimilikinya. Padahal jika dikembangkan secara baik maka akan sangat bermakna dalam mencetak sumber daya manusia yang baik dan dapat mengembangkan kreativitas siswa.

Pengembangan kreativitas siswa dapat diterapkan dalam proses pembelajaran, salah satunya pada mata pelajaran Ilmu Pengetahuan Alam (IPA). Menurut (Kumala, 2016) IPA merupakan suatu hal yang didasarkan dari gejala alam, yang mana gejala alam tersebut akan menjadi suatu pengetahuan jika diawali dengan sikap ilmiah dan menggunakan metode ilmiah. Dari kegiatan metode ilmiah tersebut akan mendapatkan suatu ilmu atau pengetahuan yang dapat diaplikasikan bagi umat manusia. Mata pelajaran IPA adalah salah satu mata pelajaran yang lebih menekankan kepada proses dibandingkan hasil hal ini dapat dimanfaatkan untuk memberikan kesempatan siswa untuk mengeksplore kemampuannya. Pembelajaran IPA sebaiknya dilaksanakan secara inkuiri alamiah (scientific inquiry) untuk menumbuhkan kemampuan berpikir, bekerja dan bersikap ilmiah serta mengkomunikasikannya sebagai aspek penting kecakapan hidup, oleh karena itu pembelajaran IPA di SD/MI lebih menekankan pada pemberian pengalaman belajar secara langsung melalui keterampilan poses dan sikap ilmiah. Salah satu cara untuk mewujudkan kecapkapan pada abad 21 yaitu dengan menerapkan pembelajaran science, technology, engineering, and mathematic (STEM) pada pembelajaran IPA. Science, technology, engineering, and mathematic (STEM) adalah sebuah pendekatan pembelajaran yang populer ditingkat dunia yang efektif dalam menerapkan pembelajaran tematik integratif karena menggabungkan empat bidang pokok dalam pendidikan yaitu sains, teknologi, teknik dan matematika. Moree (Anggraini \& Huzaifah, 2017) menyatakan STEM merupakan suatu pendekatan dan upaya dalam menggabungkan beberapa atau keempat subjek STEM menjadi satu pelajaran yang didasarkan pada hubungan antar subjek dan masalah dunia nyata. Penerapan STEM dalam pembelajaran dapat mendorong peserta didik untuk mendesain, mengembangkan, dan memanfaatkan teknologi dan mengasah kognitif, manipulatif dan afektif serta mengaplikasikan pengetahuan (Permanasari, 2016). STEM ini sangat mendukung keterampilan peserta didik untuk menghadapi abad 21 karena menggunakan digital dalam proses pembelajaran (Maula \& Fatmawati, 2020). Menurut (Zuryanty, Hamimah, Kenedi, \& Helsa, 2020) manfaat pembelajaran STEM dari aspek teknologi dalam STEM akan membentuk siswa untuk dapat bersosialisasi, berorganisasi dan mengembangkan kreativitas sehingga dapat meningkatkan jiwa sosial dan kekreativitasan siswa. Tujuan STEM untuk siswa adalah siswa mempunyai literasi STEM, menguasi kompetensi abad 21, terlibat aktif dalam proses pembelajaran (Mulyani, 2019).

Dalam proses pembelajaran IPA berbasis STEM perlu adanya media yang dapat menunjang proses pelaksanaanya agar pembelajaran lebih menarik dan dapat mencapai tujuan pembelajaran sehingga dapat mengembangkan kreativitas siswa. Peran guru selain sebagai motivator, fasilitaor juga berperan dalam berinovasi mengembangkan media yang dapat mendukung proses pembelajaran, sehingga proses pembelajaran tidak membosankan khususnya pada mata pelajaran IPA, guru harus dapat membuat media yang dapat menunjang proses pembelajaran agar tujuan pembelajaran dapat tercapai. Media Pembelajaran adalah segala bentuk dan sarana penyampaian informasi yang dibuat atau dipergunakan sesuai dengan teori pembelajaran, dapat digunakan untuk tujuan pembelajaran dalam menyalurkan pesan, merangsang pikiran, perasaan dan kemauan siswa sehingga dapat mendorong terjadinya proses belajar yang disengaja, bertujuan, dan terkendali (Suryani, Setiawan, \& Putria, 2018).

Berdasarkan observasi dan wawancara yang dilaksanakan di SDIT Khoiru Ummah hasilnya yaitu dalam proses pembelajaran guru belum menggunakan media pembelajaran yang bervariasi dan masih menggunakan bahan ajar yang berfokus pada buku paket sekolah sehingga masih belum mengembangkan kreativitas siswa dengan baik dalam proses pembelajaran. Salah satu media yang dapat digunakan dalam proses pembelajaran 
5027 Pengembangan Media Articulate Storyline 3 pada Pembelajaran IPA Berbasis STEM untuk Mengembangkan Kreativitas SiswaSD/MI - Siti Nurmala, Retno Triwoelandari, Muhammad Fahri

DOI : https://doi.org/10.31004/basicedu.v5i6.1546

adalah dengan menggunakan media articulate storyline 3, software ini dapat dimanfaatkan untuk membuat media pembelajaran IPA berbasis STEM. Articulate storyline 3 adalah perangkat lunak (software) yang difungsikan sebagai media presentasi. Articulate storyline 3 digunakan dalam mempresentasikan informasi dengan tujuan tertentu (sesuai dengan tujuan pengguna) (Pratama, 2019). Media pembelajaran ini didukung dengan fitur-fitur tersebut dapat menunjang pembuatan media pembelajaran yang menarik, selain didukung dengan fitur yang menarik media ini juga mudah dioperasikan dan dapat dikombinasikan dengan audio, video dan sebagainya. Dengan pengembangan media tersebut diharapkan dapat mengembangkan kreativitas siswa. Berdasarkan uraian dari pernasalahan di atas maka peneliti tertarik untuk melakukan penelitian dengan judul Pengembangan Media Pembelajaran Articulate Storyline 3 pada Pembelajaran IPA Berbasis STEM untuk Mengembangkan Kreativitas Siswa.

\section{METODE PENELITIAN}

Penelitian ini termasuk ke dalam jenis penelitian dan pengembangan atau research and development (R\&D). Menurut (Sugiyono, 2019) penelitian dan pengembangan atau research and development adalah metode penelitian yang digunakan untuk menghasilkan produk tertentu, dan menguji keefektifan produk tersebut. Sedangkan menurut Borg and Gall (Sugiyono, 2019) research and development (R\&D) adalah proses atau metode yang digunakan untuk memvalidasi dan mengembangkan produk, yang dimaksud produk disini tidak hanya suatu yang berupa teks, film untuk pembelajaran, dan software (perangkat lunak) komputer, tetapi juga metode seperti metode mengajar dan program pendidikan lainnya. Media pembelajaran articulate storyline 3 dikembangkan dengan model pengembangan ASSURE. Model ASSURE adalah suatu petunjuk dan perencanaan yang bisa membantu untuk bagaimana cara merencanakan, mengidentifikasi, menentukan tujuan, memilih metode, dan bahan serta evaluasi (Achmadi, Suharno, \& Suryani, 2014). Menurut (Purwanti, 2015) ada 6 tahapan dalam pengembangan model ASSURE, yaitu analyze learners (menganalisis pembelajar), state standard objectives (menentukan standar dan tujuan), select srategy, technology, media and materials (memilih strategi, teknologi, media dan materi), untilze technology media and materials (menggunakan teknologi, media, dan materi), require learner participation (mengembangkan partisipasi siswa), evluate and revise (mengevaluasi dan merevisi).

Penelitian ini dilaksanakan di kelas 4 SDIT Khoiru Ummah, Kecamatan Lewuwisadeng, Kabupaten Bogor. Subjek dalam penelitian ini yaitu siswa kelas 4 A dan Kelas 4 B. Penelitian ini dilakukan dalam 2 periode. Pertama dilaksanakan pada bulan Juli dan Agustus yaitu studi pendahuluan untuk mengetahui permasalahan pada proses pembelajaran di SDIT Khiru Ummah, kedua tahap pengembangan produk media articulate storyline 3 dilaksanakan pada tanggal 2 dan 4 September 2021. Pengembangan media articulate storyline 3 melalui tahap validasi oleh ahli materi, ahli media, dan ahli bahasa. Dan selanjutnya melalui tahap uji coba perorangan, uji coba kelompok kecil dan uji coba kelompok besar. Teknik analisis data menggunakan teknik analisis deskriptif kualitatif dan deskriptif kuantitatif. Analisis deskriptif kuantitatif digunakan untuk menghitung lembar observasi dalam mengamati kreativitas siswa, selanjutnya data dianalisis dengan menggunakan aplikasi SPSS 25 for windows.

\section{HASIL DAN PEMBAHASAN}

Pengembangan media pembelajaran articulate storyline 3 pada pembelajaran IPA berbasis STEM melalui prosedur pengembangan dengan model ASSURE. Dalam penelitian ini mengembangkan media articulate storyline 3, media ini termasuk ke dalam jenis media multimedia interaktif karena dalam media pembelajaran articulate storyline 3 terdiri dari audio, video, teks, gambar, animasi dan sebaginya. Seperti pendapat dari (Cahyadi, 2019) media multimedia adalah media yang dapat menyajikan unsur media secara 
5028 Pengembangan Media Articulate Storyline 3 pada Pembelajaran IPA Berbasis STEM untuk Mengembangkan Kreativitas SiswaSD/MI - Siti Nurmala, Retno Triwoelandari, Muhammad Fahri

DOI : https://doi.org/10.31004/basicedu.v5i6.1546

lengkap seperti, teks, grafis, gambar, video, audio dan animasi secara terintegrasi. Langkah-langkah pembuatan media pembelajaran articulate storyline 3 yaitu, menginstal software articulate storyline 3 pada laptop/PC, menyusun dan mengumpulkan bahan materi yang akan dijadikan pada media pembelajaran seperti gambar, audio, video, animasi, dan materi pelajaran, membuat media dengan software articulate storyline 3 dan memasukan bahan materi yang sudah dikumpulkan, membuat latihan interaktif, dan soal-soal evaluasi disesuaikan dengan materi yang sudah dibuat, mempublish hasil. Hasil penerbitan articulate storyline 3 berbais web (html5) atau berbentuk aplication file yang bisa dijalankan pada berbagai instrumen seperti laptop, tablet, smartphone maupun handpone (Sapitri \& Bentri, 2020). Peneliti mengembangkan produk media pembelajaran articulate storyline 3 pada kelas 4, Tema 1 "Indahnya Kebersamaan", dengan Sub Tema 1 "Keberagaman Budaya Bangsaku" mata pelajaran IPA, materi bunyi. Setelah media sudah selesai dibuat maka tahap selanjutnya yaitu melakukan validasi untuk mengetahui kelayakan media articulate storyline 3 pada ahli materi, ahli media, dan ahli bahasa berikut kriteria penilaian kevalidan media pembelajaran articulate storyline 3 :

Tabel 1. Kriteria Penilaian Kevalidan

\begin{tabular}{lll}
\hline Presentase (\%) & $\begin{array}{l}\text { Tingkat } \\
\text { Kevalidan }\end{array}$ & Kriteria Kelayakan \\
\hline $81 \%-100 \%$ & Sangat Valid & Tidak Revisi \\
\hline $61 \%-80 \%$ & Valid & Tidak Revisi \\
\hline $41 \%-60 \%$ & Cukup Valid & Perlu Revisi \\
\hline $21 \%-40 \%$ & Kurang Valid & Revisi \\
\hline $0 \%-20 \%$ & Tidak Valid & Revisi Total \\
\hline
\end{tabular}

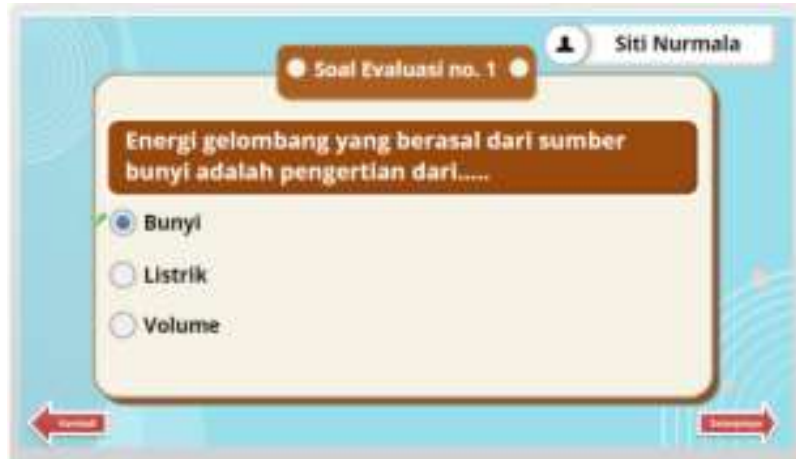

Gambar 1 : Validasi Materi Sebelum direvisi

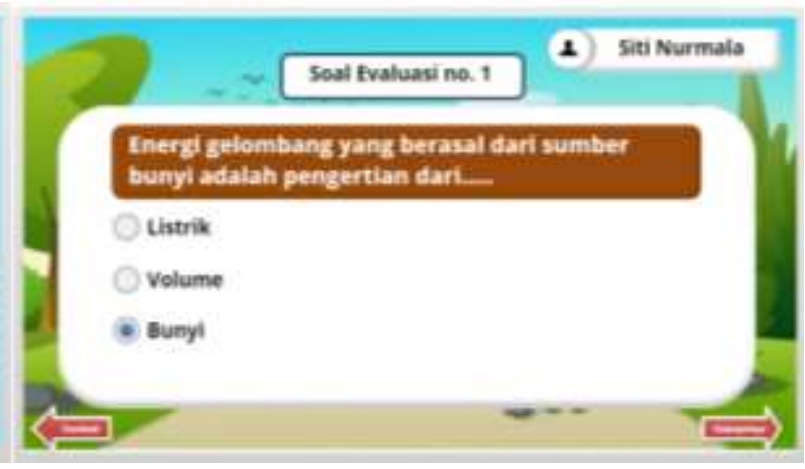

Gambar 2 :Validasi Materi sebelum direvisi

Hasil penilaian dari ahli materi memperoleh presentase tingkat kelayakan sebesar 79,8\% dengan kategori valid. Ahli materi memberikan saran kepada pengembang untuk menambah animasi dan variasi warna pada produk media articulate storyline 3 agar terlihat menarik oleh siswa.

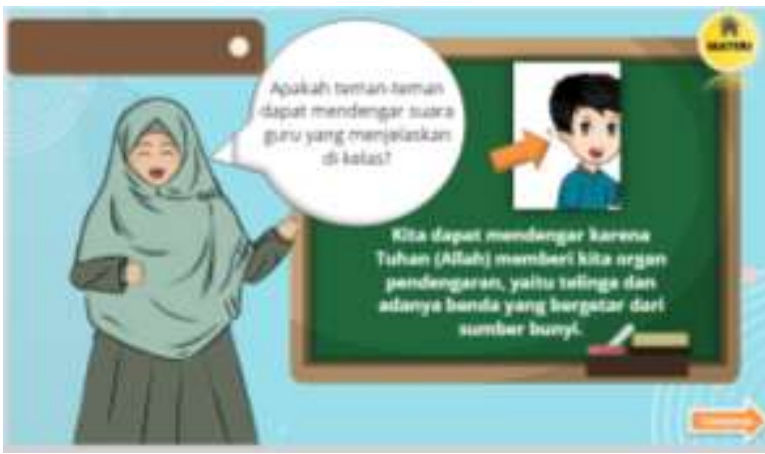

Gambar 3 :Validasi Media sebelum direvisi

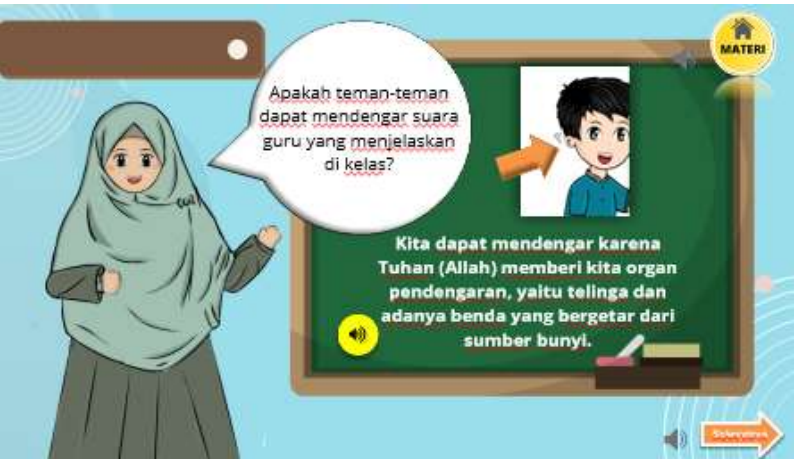

Gambar 4 : ValidasiMedia setelah direvisi 
Hasil penilaian dari ahli media memperoleh presentase tingkat kelayakan sebesar 97,9\%, dengan kategori sangat valid. Ahli media memberikan saran kepada pengembang untuk merubah ekspresi pada animasi media agar terlihat menarik oleh siswa, dan menambahkan sound pada setiap slide agar siswa dapat memahami materi dengan audio dan visual.

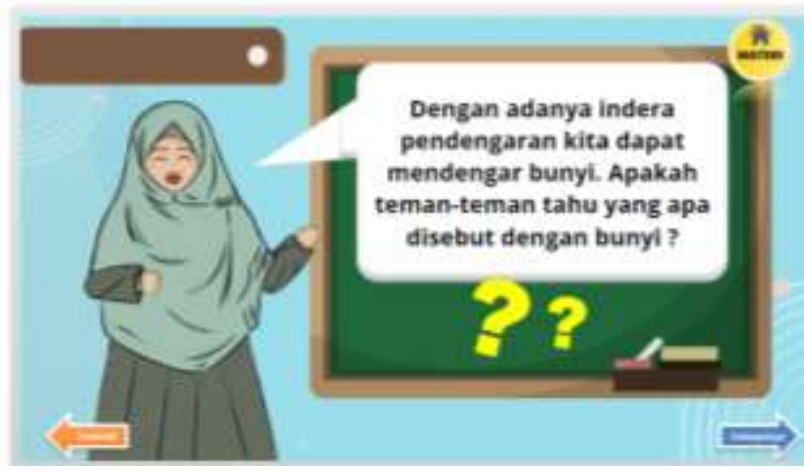

Gambar 5 : Validasi Bahasa sebelum direvisi

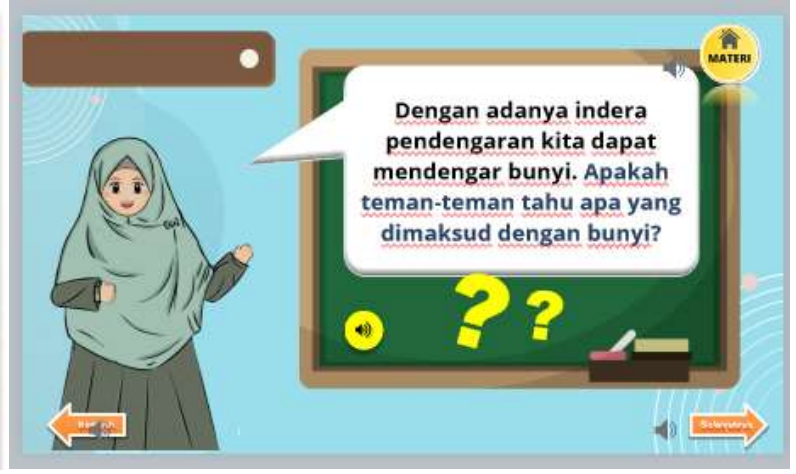

Gambar 6 : Validasi Bahasa setelah direvisi

Hasil penilaian dari ahli bahasa memperoleh presentase tingkat kelayakan sebesar 87,5\%, dengan kategori sangat valid. Ahli bahasa memberikan saran kepada pengembang untuk memperbaiki tanda baca yang kurang tepat, memperbaiki penggunaan kalimat sesuai dengan pedoman umum ejaan Bahasa Indonesia (PUEBI), dan memperbaiki kalimat yang sulit dipahami oleh siswa.

Setelah produk media articulatestoryline 3 selesai divalidasi oleh ahli dan dinyatakan layak untuk digunakan, maka langkah selanjutnya yaitu melakukan uji coba. Uji coba ini dilakukan untuk mengetahui respon siswa terhadap produk media pembelajaran articulate storyline 3 dan terbagi menjadi tiga tahap yaitu, uji perorangan, uji kelompok kecil dan uji kelompok besar. Hasil penilaian yang diperoleh dari respon siswa uji perorangan yang terdiri dari 3 responden sebesar 95,02\% dengan kategori sangaat valid, hasil uji kelompok kecil terdiri dari 8 responden sebesar 95,05\% dengan kategori sangaat valid, dan hasil uji kelompok besar terdiri dari 15 responden sebesar 91,16\% dengan kategori sangaat valid.

Selanjutnya untuk mengetahui adanya peningkatan kreativitas siswa setelah menggunakan media articulate storyline 3 dilakukan analisis deskriptif kuantitatif dengan mengguakan SPSS 25. Sebelumnya dilakukan uji normalitas dan homogenitas terlebih dahulu jika hasilnya menunjukan distribusi normal selanjutnya dilakukan uji $\mathrm{t}$ untuk mengetahui peningkatan kreativitas siswa berdasarkan hasil pretest dan posttest pada kelas kontrol dan eksperimen dapat dilihat pada tabel berikut :

Tabel 2. Hasil Rata-rata Pretest dan Posttest

\begin{tabular}{lll}
\hline Kelas & Pretest & Posttest \\
\hline Kontrol & 13,8 & 20,7 \\
\hline Eksperimen & 18,4 & 31,7 \\
\hline
\end{tabular}

Pada tabel 2 terdapat perbedaan pada hasil pretest dan posttest kelas eksperimen dan kelas kontrol, hal tersebut menunjukan bahwa adanya peningkatan kreativitas siswa setelah menggunakan media articulate storyline 3. Namun hasil rata-rata lebih besar diperoleh oleh kelas eksperimen, karena kelas eksperimen adalah kelas yang diberikan perlakuan dengan menggunakan media articulate storyline 3 pada pembelajaran IPA berbasis STEM. 
Pengembangan Media Articulate Storyline 3 pada Pembelajaran IPA Berbasis STEM untuk Mengembangkan Kreativitas SiswaSD/MI - Siti Nurmala, Retno Triwoelandari, Muhammad Fahri

DOI : https://doi.org/10.31004/basicedu.v5i6.1546

Tabel 3. Hasil Paired Sampel T-Test Uji Kelas Eksperimen

Paired Samples Test

\begin{tabular}{|c|c|c|c|c|c|c|c|c|c|}
\hline & \multicolumn{5}{|c|}{ Paired Differences } & & & \multirow{3}{*}{$\begin{array}{l}\text { Sig. } \\
(2- \\
\text { tailed) }\end{array}$} \\
\hline & & \multirow[b]{2}{*}{ Mean } & $\begin{array}{l}\text { Std. } \\
\text { Deviatio }\end{array}$ & $\begin{array}{l}\text { Std. } \\
\text { Error }\end{array}$ & $\begin{array}{l}95 \% \\
\text { Interval } \\
\text { Difference } \\
\end{array}$ & $\begin{array}{l}\text { Confidence } \\
\text { of the }\end{array}$ & & & \\
\hline & & & $\mathrm{n}$ & Mean & Lower & Upper & $\mathrm{T}$ & df & \\
\hline $\begin{array}{l}\text { Pair } \\
1\end{array}$ & $\begin{array}{l}\text { PRE TEST - } \\
\text { POST TEST }\end{array}$ & $-13,33333$ & 1,75933 & ,45426 & $-14,30762$ & $-12,35905$ & $\begin{array}{l}- \\
29,352\end{array}$ & 14 & ,000 \\
\hline
\end{tabular}

Berikut pada tabel 3 diatas hasil analisis data dengan perhitungan menggunakan SPSS 25 menunjukan hasil perbedaan pretest dan posttest pada kelas eksperimen, terdapat perbedaan rata-rata sebesar -13,33333. Tanda minus (-) berarti hasil posttest lebih besar dari hasil pretest, hasil perhitungan nilai " $t$ " adalah sebesar 29,352 dengan p-values 0,000 sig (2-tailed) berarti kurang dari 0,005, maka Ho ditolak dan Ha diterima. Untuk mengetahui hasil posttest pada kelas eksperimen dan kelas kontrol maka perlu dilakukan uji Independent sampel t-test, berikut tabelnya :

Tabel 4. Independent Sampel T-Test

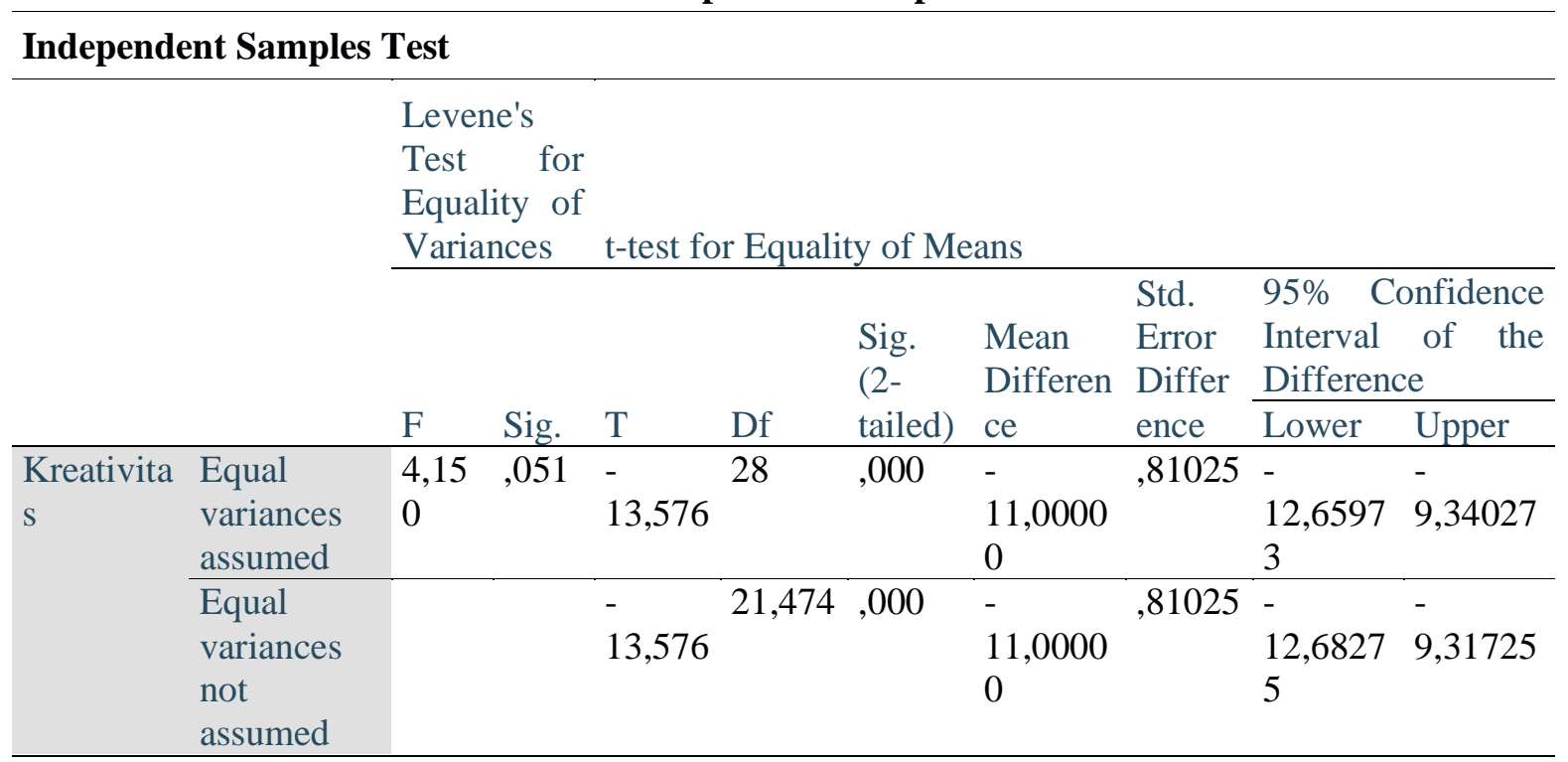

Berdasarkan tabel 4 perhitungan data independent sampel t-test yang diperoleh di atas terdapat perbedaan rata-rata pada kelas eksperimen dan kelas kontrol yaitu 11,00000 hasil tersebut diperoleh dari uji kelompok besar kelas eksperimen dan uji kelompok kecil kelas kontrol, dengan p-value sig (2-tailed) sebesar 0,000 maka Ha diterima. Dasar pengambilan keputusannya yaitu jika nilai sig (2-tailed) $<0,05$ maka Ha diterima sedangkan jika >0,05 maka Ho diterima. Berdasarkan hasil penelitian diatas menunjukan adanya perbedaan hasil antara kelas yang menggunakan media articulate storyline 3 pada pembelajaran IPA berbasis STEM dan kelas kontrol yang tidak menggunakan media articulate storyline 3. Pada kelas ekserimen yang menggunakan media articulate storyline 3 terlihat adanya peningkatan kreativita siswa.

Efektivitas produk media pembelajaran articulate storyline 3 dilakukan dengan melakukan tahapan uji perorangan, uji kelompok kecil, dan uji kelompok besar. Hal tersebut dilakukan untuk mengukur keefektifan media articulate storyline 3 pada pembelajaran IPA berbasis STEM dalam mengembangkan kreativitas siswa. Pada tahap uji coba peneliti melakukan observasi langsung terhadap siswa pada proses pembelajaran untuk 
5031 Pengembangan Media Articulate Storyline 3 pada Pembelajaran IPA Berbasis STEM untuk Mengembangkan Kreativitas SiswaSD/MI - Siti Nurmala, Retno Triwoelandari, Muhammad Fahri

DOI : https://doi.org/10.31004/basicedu.v5i6.1546

mengamati kreativitas siswa dengan dua situasi yaitu pada saat sebelum menggunakan media articulate storyline 3 dan setelah menggunakan articulate storyline 3 data ini diperoleh dari kelas eksperimen hasil pretest dan posttest. Pada uji perorangan dilakukan pada 3 responden, uji kelompok kecil dilakukan pada 8 responden, dan uji kelompok besar dilakukan pada 15 responden.

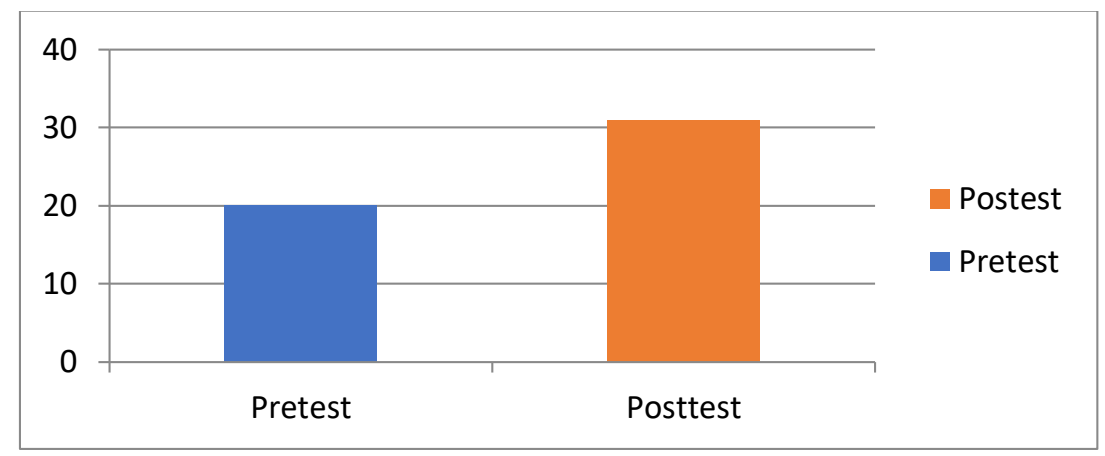

Gambar 7: Grafik Efektifitas Uji Perorangan

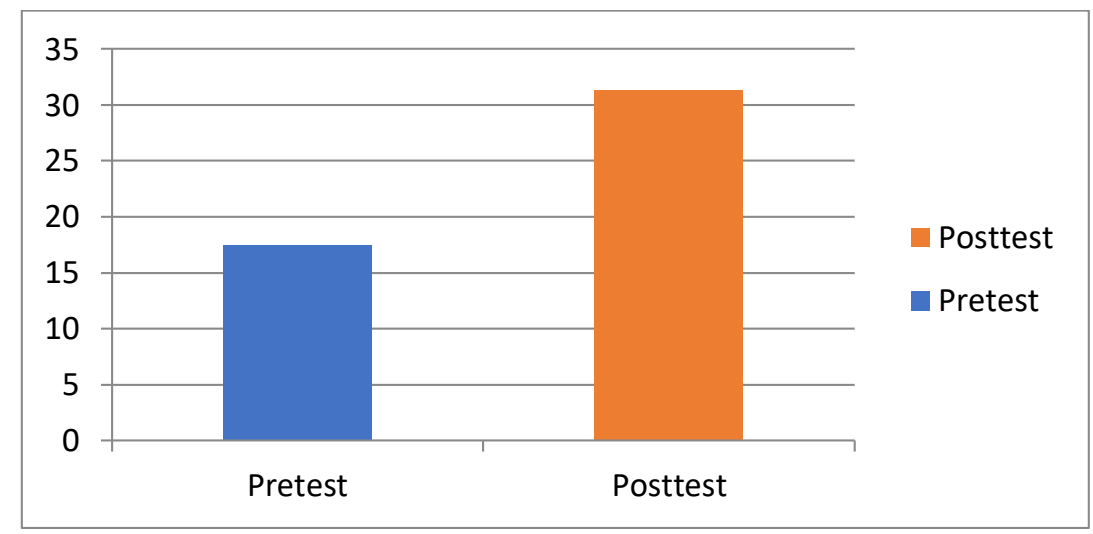

Gambar 8 : Grafik Efektifitas Uji Kelompok Kecil

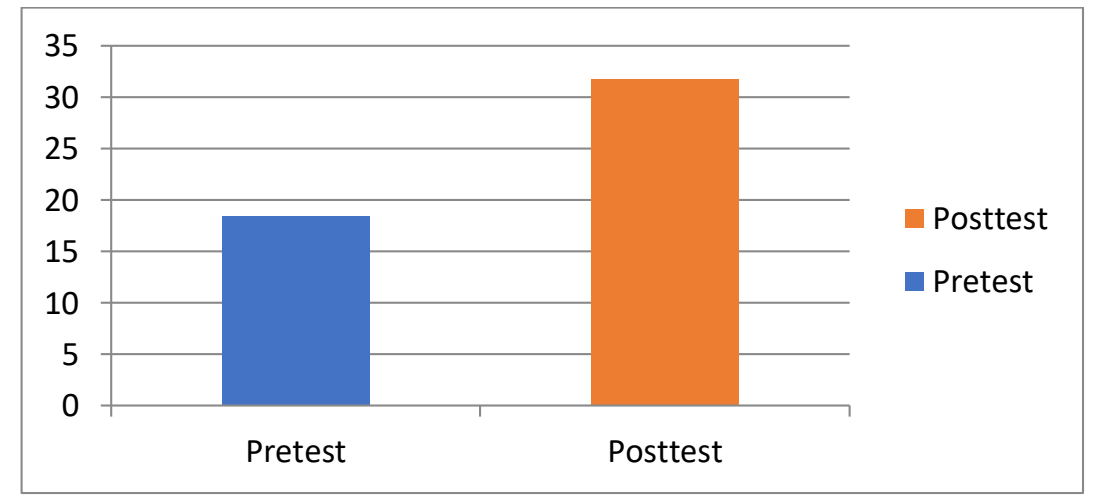

Gambar 9 :Grafik Efektifitas Uji Kelompok Besar

Pada gambar grafik efektifitas uji perorangan, uji kelompok kecil dan uji kelompok besar, terlihat bahwa adanya peningkatan setelah menggunakan media articulate storyline 3 pada pembelajaran IPA berbasis STEM dalam meningkatkan kreativitas siswa pada uji perorangan yang dilakukan pada 3 responden hasil pretest sebesar 20 dan hasil post test sebesar 31 maka terdapat perbedaan rata-rata sebesar 11. Pada uji kelompok kecil yang dilakukan pada 8 responden hasil pretest sebesar 17,4 dan hasil post test sebesar31,1 maka terdapat perbedaan rata-rata sebesar 13,7. Pada uji kelompok besar yang dilakukan pada 15 responden 
5032 Pengembangan Media Articulate Storyline 3 pada Pembelajaran IPA Berbasis STEM untuk Mengembangkan Kreativitas SiswaSD/MI - Siti Nurmala, Retno Triwoelandari, Muhammad Fahri

DOI : https://doi.org/10.31004/basicedu.v5i6.1546

hasil pretest sebesar18,4 dan hasil post test sebesar 31,7 maka terdapat perbedaan rata-rata sebesar 13,3. Maka dari data tersebut dapat disimpulkan bahwa media articulate storyline 3 efektif digunakan dalam proses pembelajaran IPA berbasis STEM untuk mengembangkan kreativitas siswa.

Berdasarkan pada hasil penelitian di atas, pengembangan media articulate storyline 3 ini dikembangkan dengan model ASSURE. Langkah-langkah yang dilakukan dalam pengembangan yaitu, pertama, analyze learners (menganalisis pembelajar) pada tahap ini menganalisis situasi pembelajar, berdasarkan pada hasil dari wawancara dan observasi di SDIT Khoiru Ummah guru masih kurang bervariasi dalam menggunakan media pembelajaran, dan siswa kelas 4 memiliki karakteristik yang berbeda baik dari sikap, gaya belajar sehingga perlu adanya media yang dapat membantu dalam proses pembelajaran dengan gaya belajar siswa yang berbeda tersebut; state standard and objective (menentukan standar dan tujuan) pada tahap ini peneliti merumuskan tujuan pembelajaran yang sesuai dengan yang ada pada silabus tematik pada mata pelajaran IPA. Dalam penelitian ini dilakukan pada kelas 4 SDIT Khoiru Ummah, Tema 1 "Indahnya Kebersamaan", dengan Sub Tema 1 "Keberagaman Budaya Bangsaku" materi IPA untuk mengembangkan kreativitas siswa; select srategy, technology, media and material (memilih strategi, teknologi, media dan materi). Berdasarkan hasil analisis di atas strategi, metode, media dan materi disesuaikan dan dikemas dalam media pembelajaran interaktif yang dapat meningkatkan kreativitas siswa. Strategi pembelajaran yang dipilih adalah pembelajaran IPA berbasis STEM karena pembelajaran berbasis STEM lebih menekankan pada proses sehingga siswa dapat terlibat secara aktif dalam proses pembelajaran dan dapat meningkatkan kreativitas siswa. Media yang dipilih yaitu media pembelajaran interaktif articulate storyline 3, media ini dibuat dengan tampilan yang menarik sehingga tidak membosankan saat digunakan dalam proses pembelajaran.; untilze technology media and materials (menggunakan teknologi, media, dan materi) pada tahap ini menggunakan teknologi, media, dan materi yang sudah ditentukan sebelumnya. Media yang dikembangkan yaitu media articulate soryline 3; require learner participation (mengembangkan partisipasi siswa) pada tahap ini yaitu melibatkan siswa berpartisipasi aktif dalam proses pembelajaran, siswa berani mengemukakan pendapat, dan memiliki rasa ingin tahu yang tinggi dalam proses pembelajaran dengan menggunakan media articulate storyline 3; evluate and revise (evaluasi dan revisi), evaluasi dan revisi ini dilakukan setelah penilaian oleh ahli, dan respon siswa setelah menggunakan media articulate storyline 3 untuk mengetahui kekurangan dan hal-hal yang perlu diperbaiki, agar produk media articulate storyline 3 menjadi lebih baik.

Sebelum media dilakukan uji coba dilapangan, maka dilakukan tahap valiadasi kepada tiga ahli terlebih dahulu, yaitu ahli materi, ahli media dan bahasa. Hasil penilaian ahli materi sebesar 79,8\% dengan kategori valid, hal ini menunjukan bahwa media articulate storyline 3 baik dari segi kelayakan isi, kekauratan materi, kekauratan istilah, gambar dan contoh-contoh yang ada pada media articulate storyline 3 dan pada kelayakan penyajian. Hasil penilaian ahli media sebesar 97,9\%, dengan kategori sangat valid, dari valiadasi diatas menunjukan bahwa media articulate storyline 3 baik untuk digunakan karena bersifat interaktif dilengkapi tampilan media yang menarik, desain, ilustrasi, gambar-gambar dan dilengkapi audio sehingga membuat pembelajaran tidak membosankan. Hasil penilaian ahli bahasa sebesar 87,5\%, dengan kategori sangat valid, hal tersebut menunjukan bahwa media articulate storyline 3 baik dari segi kebahasaan dan mudah dipahami siswa.

Media articulate storyline 3 dilakukan uji coba kepada kelas eksperimen dan kelas kontrol. kelas eksperimen yaitu kelas yang mendapatkan perlakuan dengan menggunakan media articulate storyline 3 saat proses pembelajaran sedangkan kelas kontrol adalah kelas yang tidak mendapatkan perlakukan yaitu tidak menggunakan media articulate storyline 3 dalam proses pembelajaran. Peneliti melakukan observasi terkait kreativitas siswa hasil pada kelas kontrol sebesar 20,7 sedangkan hasil pada kelas eksperimen sebesar 31,7 terdapat perbedaan sebesar 11, maka dapat disimpulkan adanya peningkatan kreativitas siswa yang menggunakan media articulate storyline 3. Berdasarkan data tersebut sejalan dengan pendapat Lautfer dalam (Tafonao, 2018) menjelaskan bahwa media pembelajaran sebagai salah satu alat bantu mengajar bagi guru 
5033 Pengembangan Media Articulate Storyline 3 pada Pembelajaran IPA Berbasis STEM untuk Mengembangkan Kreativitas SiswaSD/MI - Siti Nurmala, Retno Triwoelandari, Muhammad Fahri

DOI : https://doi.org/10.31004/basicedu.v5i6.1546

untuk menyampaikan materi pengajaran, meningkatkan kreativitas dan perhatian siswa dalam proses pembelajaran.

Media pembelajaran articulate storyline 3 ini efektif digunakan dalam proses pembelajaran karena media articulate storyline 3 memiliki banyak kelebihan. Menurut (Santyasa, Juniantari, \& Santyadiputra, 2020) kelebihan dari media articulate storyline 3 adalah sebagai berikut, desain antar muka yang fungsional dan mudah digunakan, dapat menghasilkan media interaktif sesuai storyline yang dibuat, dapat didistribusikan ke berbagai paltform e-learning masa kini yang berbasis web, mudah digunakan karena tampilan awal yang seperti power point akan memudahkan pengguna baru dalam menggunakannya. Media articulate storyline 3 ini efektif digunakan dalam proses pembelajaran karena berdasarkan respon siswa, siswa sangat senang belajar dengan menggunakan media articulate storyline 3 karena tampilan media yang menarik dan tidak membosankan, serta materi yang mudah dipahami membuat siswa antusias dan semangat mengikuti pembelajaran. Setelah dilakukan uji coba perorangan, uji kelompok kecil, dan uji kelompok besar terdapat peningkatan kreativitas siswa setelah menggunakan articulate storyline 3 dalam proses pembelajaran.

\section{KESIMPULAN}

Berdasarkan hasil penelitian dan pengembangan yang telah dilakukan maka dapat disimpulkan bahwa media articulate storyline 3 layak dan efektif digunakan pada pembelajaran IPA berbasis STEM untuk mengembangkan kreativitas siswa. Hal ini dapat dilihat pada hasil validasi oleh ahli dalam penilaian kelayakan media articulate storyline 3 dari aspek materi sebesar 79,8\% dengan kategori valid, aspek media sebesar 97,9\% dengan kategori sangat valid, dan pada aspek bahasa sebesar 87,5\% dengan kategori sangat valid. Media pembelajaran articulate storyline 3 juga dapat meningkatkan kreativitas siswa karena terdapat perbedaan antara nilai rata-ratakelas kontrol dan kelas eksperimen yaitu sebesar 11,00000 dengan sig (2tailed) sebesar 0,000. Maka dapat disimpulkan media articulate storyline 3 efektif dan layak digunakan pada pembelajran IPA berbasis STEM untuk meningkatkan kreativitas siswa.

\section{DAFTAR PUSTAKA}

Achmadi, H., Suharno, \& Suryani, N. (2014). Penerapan Model Assure Dengan Menggunakan Media Power Point Dalam Pembelajaran Bahasa Inggris Sebagai Usaha Peningkatan Motivasi Dan Prestasi Belajar Siswa Kelas X Man Sukoharjo Tahun Pelajaran 2012/2013. Jurnal Teknologi Pendidikan Dan Pembelajaran, 2(1), 37. Retrieved From Http://Jurnal.Fkip.Uns.Ac.Id

Anggraini, F. I., \& Huzaifah, S. (2017). Implementation Of Stem Learning In Secondary Schools. Program Studi Pendidikan Biologi Fakultas Keguruan Dan Ilmu Pendidikan Universitas Sriwijaya, 4(1998), 724. Retrieved From Http://Conference.Unsri.Ac.Id/Index.Php/Semnasipa/Article/View/738

Cahyadi, A. (2019). Pengembangan Media Dan Sumber Belajar. Retrieved From Http://Idr.UinAntasari.Ac.Id/16140/1/Ani Cahyadi Pengembangan Media \%28book\%29.Pdf

Kumala, F. N. (2016). Pembelajaran Ipa Sekolah Dasar. Retrieved From Https://Repository.Unikama.Ac.Id/691/1/Pembelajaran Ipa Sd.Pdf

Maknun, D., Genisa, M. U., Pamungkas, T., Hernawati, K., Purnomo, J., Khikmawati, M. N., \& Tamimuddin, M. (2018). Sukses Mendidik Anak Di Abad 21. Yogyakarta: Samudra Biru.

Maula, N. R., \& Fatmawati, L. (2020). Pengembangan Media Pembelajaran Kayaku (Kayanya Alam Negeriku) Berbasis Stem Kelas Iv Sekolah Dasar. Jurnal Ilmiah Sekolah Dasar, 4(1), 99. Https://Doi.Org/10.23887/Jisd.V4i1.22351

Mulyani, T. (2019). Pendekatan Pembelajaran Stem Untuk Menghadapi Revolusi Industry 4.0. Seminar Nasional Pascasarjana 2019, 7(1), 456. Retrieved From File:///C:/Users/User/Downloads/Mulyani- 
5034 Pengembangan Media Articulate Storyline 3 pada Pembelajaran IPA Berbasis STEM untuk Mengembangkan Kreativitas SiswaSD/MI - Siti Nurmala, Retno Triwoelandari, Muhammad Fahri DOI : https://doi.org/10.31004/basicedu.v5i6.1546

Pendekatan Pembelajaran Stem.Pdf

Munandar, U. (2016). Pengembangan Kreativitas Anak Berbakat. Jakarta: Rineka Cipta.

Permanasari, A. (2016). Stem Education: Inovasi Dalam Pembelajaran Sains. Prosiding Snps (Seminar Nasional Pendidikan Sains), $23-34$. Https://Jurnal.Fkip.Uns.Ac.Id/Index.Php/Snps/Article/Viewfile/9810/7245

Pratama, R. A. (2019). Media Pembelajaran Berbasis Articulate Storyline 2 Pada Materi Menggambar Grafik Fungsi Di Smp Patra Dharma 2 Balikpapan. Jurnal Dimensi, 7(1), 19-35. Https://Doi.Org/10.33373/Dms.V7i1.1631

Purwanti, B. (2015). Pengembangan Media Video Pembelajaran Matematika Dengan Model Assure. Jurnal Kebijakan Dan Pengembangan Pendidikan, $42-47$. Http://Ejournal.Umm.Ac.Id/Index.Php/Jmkpp/Article/View/2194

Rachmawati, Y., \& Kurniati, E. (2011). Strategi Pengembangan Kreativitas Pada Anak. Jakarta :Kencana. Https://Books.Google.Co.Id/Books?Id=Nwrbdwaaqbaj

Santyasa, I. W., Juniantari, M., \& Santyadiputra, G. S. (2020). Efektivitas Pelatihan Pembuatan Media Pembelajaran Interaktif Berbasis Articulate Storyline 3 Untuk Guru-Guru Di Sma N 2 Singaraja. Proceeding Senadimas Undiksha, (4), 1784-1790.

Sapitri, D., \& Bentri, A. (2020). Pengembangan Media Pembelajaran Berbasis Aplikasi Articulate Storyline Pada Mata Pelajaran Ekonomi Kelas X Sma. Inovtech, 2(01), 3. Http://Inovtech.Ppj.Unp.Ac.Id/Index.Php/Inovtech/Article/View/115

Sugiyono. (2019). Metode Penelitian \& Pengembangan Research And Development. Bandung: Alfabeta.

Sugiyono. (2019). Metode Penelitian Kuantitatif, Kualitatif Dan R\&D. Bandung: Alfabeta.

Suryani, N., Setiawan, A., \& Putria, A. (2018). Media Pembelajaran Inovatif Dan Pengembangannya. Bandung: Pt Remaja Rosdakarya.

Susanto, A. (2016). Teori Belajar Dan Pembelajaran. Jakarta: Kencana.

Tafonao, T. (2018). Peranan Media Pembelajaran Dalam Meningkatkan Minat Belajar Mahasiswa. Jurnal Komunikasi Pendidikan, 2(2), 103. Https://Doi.Org/10.32585/Jkp.V2i2.113

Zuryanty, Hamimah, Kenedi, A. K., \& Helsa, Y. (2020). Pembelajaran Stem Di Sekolah Dasar. Yogyakarta : Deepublish. Https://Books.Google.Co.Id/Books?Id=Zaaaeaaaqbaj 